\title{
Selection of Early Lines without Frost Damage Based on Parameters of Accumulated Temperature for Flushing and Opening Speed of New Leaves in Tea
}

\author{
Hide OMAE ${ }^{1 *}$ and Yoshiyuki TAKEDA ${ }^{2}$ \\ ${ }^{1}$ Okinawa Subtropical Station, Japan International Research Center for Agricultural Sciences \\ (Ishigaki, Okinawa 907-0002, Japan) \\ 2 Department of Tea, National Institute of Vegetable and Tea Science \\ (Makurazaki, Kagoshima 898-0032, Japan)
}

\begin{abstract}
Given the demand by farmers for early budding cultivars in tea, this study was carried out to select moderately early lines without frost damage, as well as lines showing rapid growth after flushing among 1,300 tea (Camellia sinensis) accessions preserved at the Makurazaki Station of the National Institute of Vegetable and Tea Science, Japan. A model for flushing and leaf opening $\left[y=(a x+b)^{0.5}, y\right.$ : number of open leaves, $\mathrm{x}$ : effective accumulated temperature calculated by integrating values of temperatures being $10^{\circ} \mathrm{C}$ below the daily minimum air temperature since the date of autumn skiffing and a, b: parameters] was developed before the selection. For the selection, the estimated parameters were used as indicators of the flushing temperature and opening speed of tea leaves. As a result, 120 moderately early lines, 79 rapidly growing lines and 12 lines (parameter a $>0.5, \mathrm{x}_{0}=145-150^{\circ} \mathrm{C}$ ) with both characteristics were selected. Furthermore, Taiwan-yamacha which showed extremely late flushing characteristics, accounted for 44 of the 68 late flushing lines and is expected to be used as breeding material to extend the harvesting period for the first crop.
\end{abstract}

Discipline: Genetic resources / Plant breeding / Tea industry

Additional key words: Camellia sinensis, sensitivity to temperature

\section{Introduction}

Japanese farmers show a preference for early budding cultivars because the first crop fetches a high price. However, cultivars that flush too early may experience frost damage. Takahashi ${ }^{15}$ reported that newly flushed tea leaves experience heavy damage at temperatures below -2 to $-3^{\circ} \mathrm{C}$, while winter tea buds survive at $-9^{\circ} \mathrm{C}$. Kayumi ${ }^{6}$ pointed out that frost damage to tea buds in early spring mainly depends on the date of flushing. If late frost occurs at the time of flushing or later than the date of flushing, then tea buds may experience frost damage. Therefore, an early tea cultivar which flushes relatively late and so avoids frost damage, as well as grows rapidly after flushing, would certainly contribute sufficiently to tea cultivation. Therefore, early tea lines were selected from tea accessions of the National Institute of Vegetable and Tea Science (NIVTS) which preserves over 4,000 samples of tea germplasm collected from various countries.

Before the screening, a strategy was developed to select early lines characterized by earliness and rapid growth after flushing. For screening early lines, the early flushing characteristic was evaluated very carefully, because tea buds must be protected from late frost in early spring. However, it is difficult to evaluate this characteristic because it changes depending on the weather conditions in that period. In addition, the evaluation of the leaf opening speed is difficult too, because it also depends on the weather and bud conditions. Many tea farmers often do not understand that early cultivars flush earlier than other cultivars but grow slowly after flushing. In contrast, late cultivars flush late but grow quickly. Therefore, rapidly growing lines can be obtained from late lines. However, this concept is not correct because the observations are not based on the genetic characteristics for leaf opening.

*Corresponding author: fax +81-980-82-0614; e-mail homae@affrc.go.jp

Received 3 March 2003; accepted 16 June 2003. 
Because of the failure in screening due to such misconceptions, we focused on the parameter of effective accumulated temperature. There are numerous reports indicating that temperature is a key factor for the regulation of flushing and growth of tea buds ${ }^{4,5,8,9,12-14,17,18,22}$. Accumulated temperature or thermal time is a popular parameter among some researchers ${ }^{5}$, and is used to evaluate growth habits in tea plants. In addition, there are certain advantages in the use of model parameters for screening. First, one can screen for both early flushing and leaf opening speed based on the single genetic characteristic of temperature sensitivity. Next, the screening and analysis of each character enable to develop a better strategy for crossing to obtain superior early cultivars and avoid damage from late frost in different regions.

This study was carried out to screen for early lines that can avoid frost among our tea accessions, with model parameters to compare the sensitivity to temperature in terms of flushing and leaf opening speed. Furthermore, attempts were made to elucidate the direction of tea breeding in Japan and obtain useful information for future breeding.

\section{Materials and methods}

The tea cultivars and lines examined and evaluated in this study are listed in Table 1. Among the tea accessions, 1,300 tea cultivars and lines (688; var. assamica, and 612; var. sinensis including 163 Japanese cultivars and lines) were used. Tea (Camellia sinensis) is generally divided into two main varieties, var. sinensis and var. assamica based on morphophysiological ${ }^{1-3,11,16,19,21}$ and biochemical $^{7,10}$ traits. This classification was adopted here, but with a minor change, namely the separation of var. sinensis into two types, Japanese cultivars and other types when necessary.

The experiment was conducted with the first crop in 1998. The number of open leaves was recorded every week from February 27 to April 23, 1998. The daily minimum air temperature was obtained from the Automated Meteorological Data Acquisition System (AMeDAS) at the Makurazaki Meteorological Station, Japan.

For the model, data sets of effective accumulated temperature which were $10^{\circ} \mathrm{C}$ below the daily minimum air temperature $[\Sigma$ (daily minimum air temperature $-10)]^{17,18}$ since the date of autumn skiffing (10 November, 1997) were prepared. Second, several models for expressing bud flushing and leaf opening were designed with the data sets. Among these models, the most suitable was adopted as follows:

$$
\mathrm{y}=(\mathrm{ax}+\mathrm{b})^{0.5}
$$

where $\mathrm{y}$ is the number of open leaves, $\mathrm{x}$ is the estimated
Table 1. List of evaluated tea cultivars and lines, their sources and racial types

\begin{tabular}{|c|c|c|c|}
\hline Variety & Country & Racial type & $\begin{array}{c}\text { No. of cultivars } \\
\text { of lines }\end{array}$ \\
\hline \multirow[t]{19}{*}{ var. assamica } & Bangladesh & PKS & 185 \\
\hline & India & Abe & 10 \\
\hline & India & $\mathrm{Ai}$ & 39 \\
\hline & India & $\mathrm{Ak}$ & 229 \\
\hline & India & Alu & 1 \\
\hline & India & Ay & 4 \\
\hline & India & Clone & 3 \\
\hline & India & IND & 66 \\
\hline & India & SMP & 2 \\
\hline & India & Stock & 5 \\
\hline & Indonesia & $\mathrm{Aj}$ & 6 \\
\hline & Malaysia & Boh & 3 \\
\hline & Myanmar & BUM & 5 \\
\hline & Sri Lanka & Ace & 6 \\
\hline & Sri Lanka & SRL & 42 \\
\hline & Taiwan & $\mathrm{F}$ & 1 \\
\hline & Taiwan & Taiwan-yamacha & 59 \\
\hline & Vietnam & Ash & 1 \\
\hline & Vietnam & Shan & 21 \\
\hline \multirow[t]{13}{*}{ var. sinensis } & China & $\mathrm{C}$ & 3 \\
\hline & China & $\mathrm{Ca}$ & 7 \\
\hline & China & $\mathrm{Ch}$ & 2 \\
\hline & China & Chinese cultivars & 4 \\
\hline & China & $\mathrm{Ck}$ & 49 \\
\hline & China & $\mathrm{Cm}$ & 33 \\
\hline & China & $\mathrm{Cn}$ & 103 \\
\hline & China & $\mathrm{Cp}$ & 29 \\
\hline & China & $\mathrm{Ct}$ & 10 \\
\hline & China & Cy & 7 \\
\hline & India & $\mathrm{Cd}$ & 202 \\
\hline & Japan & Japanese cultivars & 163 \\
\hline & & Total & 1,300 \\
\hline
\end{tabular}

effective accumulated temperature which is $10^{\circ} \mathrm{C}$ below the daily minimum air temperature, and $\mathrm{a}$ and $\mathrm{b}$ are parameters. From the model, parameter a (sensitivity to temperature; a large value for parameter a indicates a higher sensitivity to temperature for leaf opening) was calculated from x from February 27 to April 23, 1998, and used as an indicator expressing the opening speed of leaves. The $\mathrm{x}_{0}$ value (the value of $\mathrm{x}$ at $\mathrm{y}=0$; effective accumulated temperature from autumn skiffing to flushing) was also used as an indicator of early flushing.

Since the newly developed model was applied to all the lines and regression lines, the values of parameters a, $\mathrm{b}$ and $\mathrm{x}_{0}$ in each line were obtained. Moreover, $\mathrm{a}, \mathrm{x}_{0}$ and its standard deviation values in Japanese cultivars were compared with those in the other types of var. sinensis to analyze their characteristics, and the past and future direction of tea breeding in Japan. 


\section{Results and discussion}

The proposed model was applied to three Japanese cultivars ('Benitatiwase', 'Yabukita' and 'Yamatomidori') which differed in the time of flushing. 'Benitatiwase' flushed earlier than the other two cultivars, showing slower leaf opening with time. In contrast, 'Yamatomidori' flushed later and displayed more rapid growth than the other cultivars (Fig. 1-a). However, a complete change in trend was observed when the number of open leaves was compared with the effective accumulated temperature (Fig. 1-b). 'Benitatiwase' showed the earliest flushing and most rapid growth among the cultivars. 'Yamatomidori', in contrast, was the latest to flush and the slowest for leaves to open. The changes in the tendency for early flushing and opening speed of leaves with effective accumulated temperature were easily identified by comparing $\mathrm{x}_{0}$ and parameter $\mathrm{a}$. The values of $\mathrm{x}_{0}$ (an indicator of early flushing) of the three cultivars, 'Benitatiwase', 'Yabukita' and 'Yamatomidori' were 148.4, 165.0 and 173.0, and the values of parameter a (an indicator of opening speed of leaves) were $0.49,0.29$ and 0.08 , respectively. The results indicated that the lower the value of $x_{0}$, the earlier the flushing, and the higher the value of parameter a, the more rapid the growth with effective accumulated temperature. The regression lines showed a high ratio of contribution $\left(\mathrm{r}^{2}\right)$ for each cultivar. The $\mathrm{x}_{0}$ and a values were used for the screening. The model was applied to all the cultivars and lines (Table 1), and regression lines
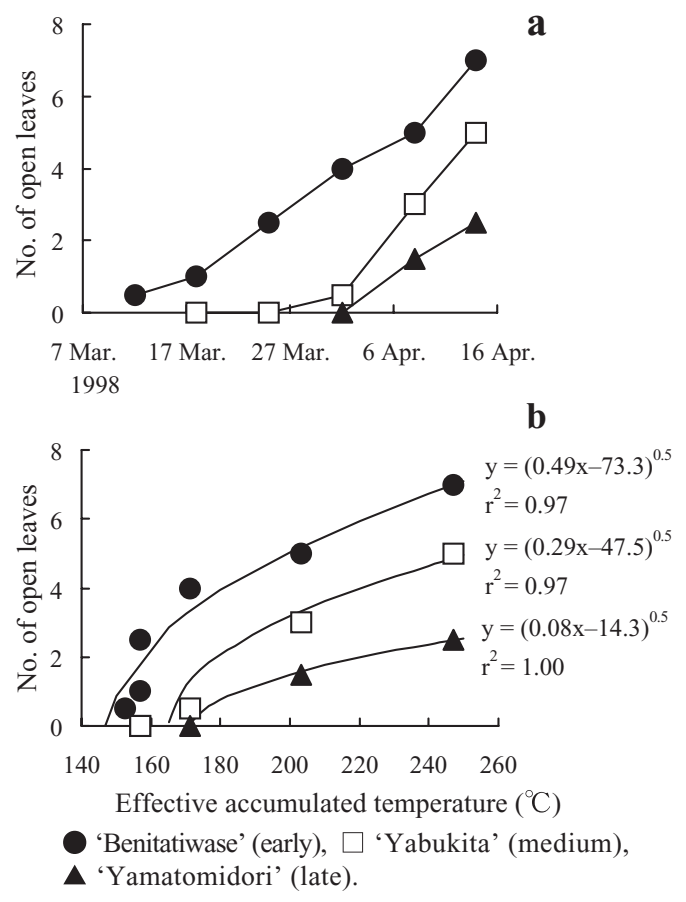

Fig. 1. Application of the model to cultivars were obtained with values for $\mathrm{a}, \mathrm{b}$ and $\mathrm{x}_{0}$ in each line. The regression lines for each cultivar and line showed high $r^{2}$ values (average: 0.953, range: 0.481-1.000). Of the 35 lines with relatively low $r^{2}$ values (less than 0.8 ), 19 belonged to var. assamica and 16 to var. sinensis. These lines showed unique characteristics, i.e. early flushing (the average value of $\mathrm{x}_{0}$ was 0.189 ) but slow growth (the average value of a was $143^{\circ} \mathrm{C}$ ). On the other hand, the 73 lines which showed higher $\mathrm{r}^{2}$ values (more than 0.997 ) mostly belonged to var. sinensis (50). These lines showed medium characteristics (Fig. 4) of flushing (average $\mathrm{x}_{0}: 0.304$ ) and growth (average a: $156^{\circ} \mathrm{C}$ ).

The distribution patterns of $\mathrm{x}_{0}$ (effective accumulated temperature from autumn skiffing to flushing; an indicator of early flushing) among cultivars and lines differed (Fig. 2), but not significantly, between the two varieties, i.e. var. assamica and var. sinensis. The average value of $\mathrm{x}_{0}$ was $156.8^{\circ} \mathrm{C}\left(125.7-184.3^{\circ} \mathrm{C}\right)$ in var. assamica and $156.4^{\circ} \mathrm{C}\left(128.9-182.0^{\circ} \mathrm{C}\right)$ in var. sinensis.

Many lines showed a slower opening of leaves in var. assamica than in var. sinensis (Fig. 3), indicating the existence of a significant difference at the 0.01 level (Tukey multiple range test). The average value of param-

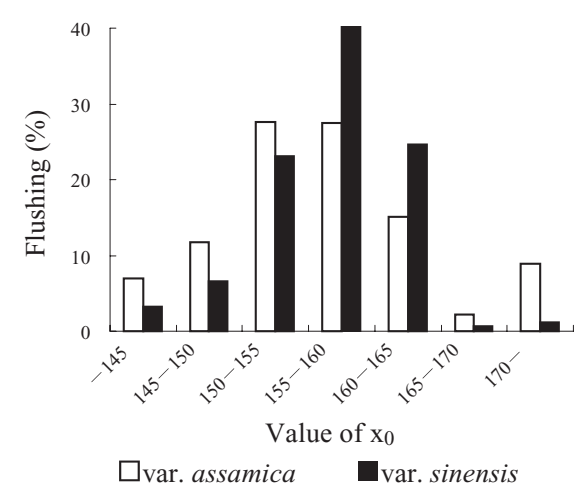

Fig. 2. Histogram of accumulated temperature for flushing

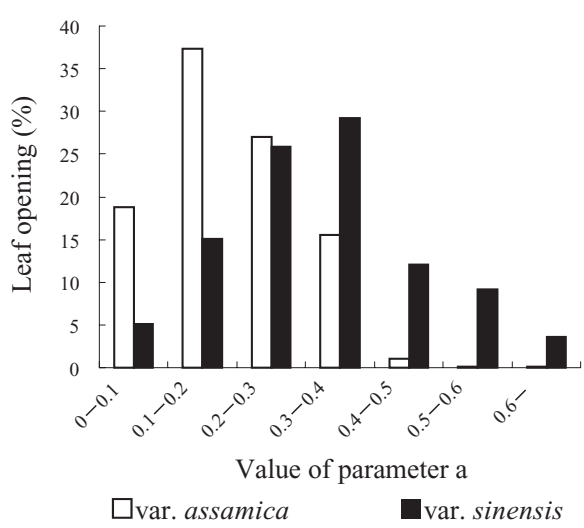

Fig. 3. Histogram of parameter a for opening speed of leaves 


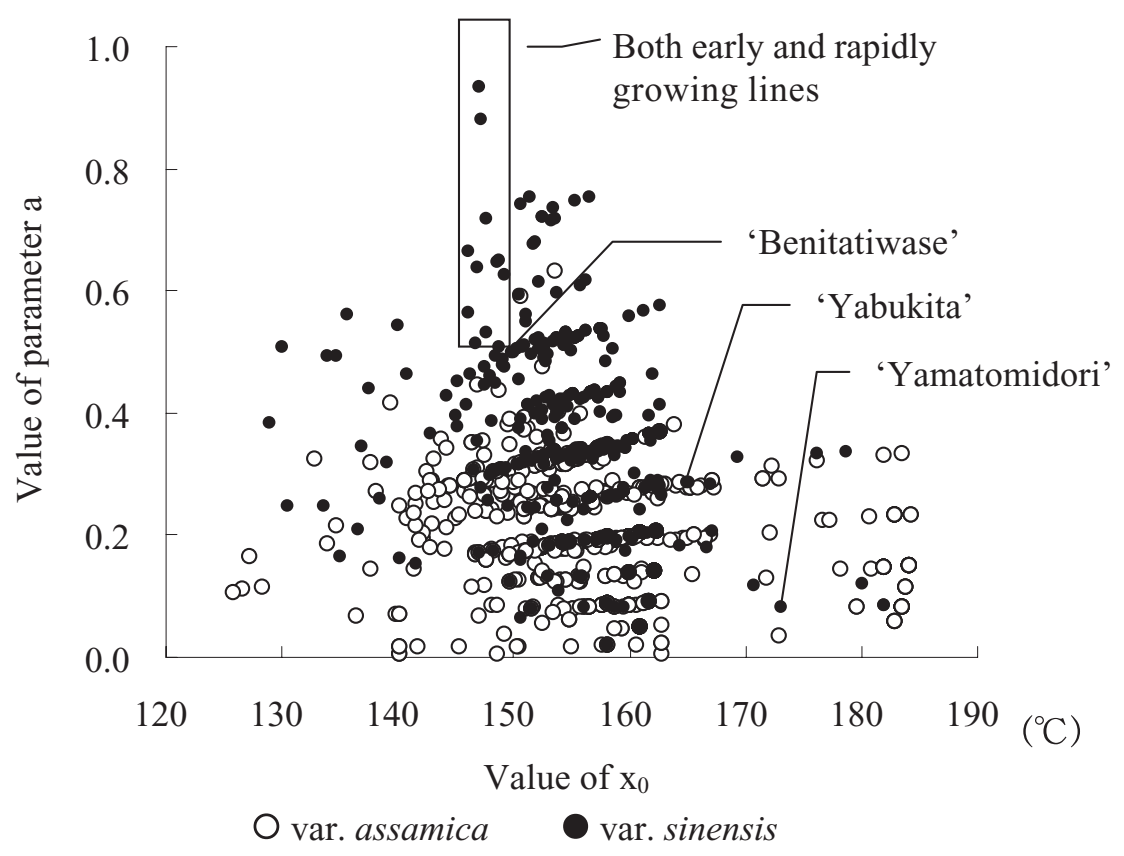

Fig. 4. Relation between $x_{0}$ and parameter a

eter a in var. assamica was 0.203 (0.004-0.630), compared to $0.320(0.020-0.940)$ in var. sinensis. Approximately $89.4 \%$ of all the cultivars and lines tested showed an effective accumulated temperature of 140 to $165^{\circ} \mathrm{C}$ and a value of less than 0.6 for parameter a (Fig. 4).

Early flushing and rapidly growing lines for leaf opening were searched for using $\mathrm{x}_{0}$ and parameter a of 'Benitatiwase' as references. As a result, 120 (81 var. assamica and 39 var. sinensis) lines that avoided frost damage $\left(\mathrm{x}_{0}=145-150^{\circ} \mathrm{C}\right), 79$ (2 var. assamica and 77 var. sinensis) rapidly growing lines (parameter a $>0.5$ ), and 12 var. sinensis lines which showed both characteristics were selected (Table 2). All the regression lines of the materials selected showed high $\mathrm{r}^{2}$ values (average: 0.930, range: 0.643-1.000). Many early lines belonged to var. assamica. The major type among var. assamica was PKS followed by Ak, IND and SRL. On the other hand, the major type of early line in var. sinensis was derived from a Japanese cultivar, followed by $\mathrm{Cd}$ and $\mathrm{Cn}$. For the rapidly growing lines, only two, PKS and Ay, were selected from var. assamica (Table 2). The major rapidly growing line in var. sinensis was selected from $\mathrm{Cd}$, followed by the Japanese cultivar and Cn. The 6 lines which displayed both earliness and rapid growth were derived from Japanese cultivars such as 'Kuritawase', 'Makinoharawase' and 'Yutakamidori'. The other 6 lines were derived from $\mathrm{Cd}, \mathrm{Cm}$ and $\mathrm{Cn}$, namely Cd163, Cd174, Cd248, Cd340, Cm19 and Cn59.

Regarding the direction of tea breeding in Japan, the results obtained revealed that tea breeding in Japan probably has two different objectives, one, to produce cultivars which show rapid growth for leaf opening, and the other, to breed different types of early cultivars to extend the harvesting period, as shown in Table 3. When the estimated values of parameter a were compared, Japanese cultivars were found to have larger values and thus to

Table 2. Selection of early and rapidly growing lines for leaf opening

\begin{tabular}{|c|c|c|c|c|}
\hline Variety & Racial type & $\begin{array}{l}\text { Early } \\
\text { lines }\end{array}$ & $\begin{array}{l}\text { Rapidly } \\
\text { growing } \\
\text { lines }\end{array}$ & $\begin{array}{c}\text { Both early } \\
\text { and rapidly } \\
\text { growing lines }\end{array}$ \\
\hline \multirow[t]{9}{*}{ var. assamica } & PKS & 37 & 1 & - \\
\hline & $\mathrm{Ak}$ & 22 & - & - \\
\hline & IND & 9 & - & - \\
\hline & SRL & 6 & - & - \\
\hline & $\mathrm{Ai}$ & 2 & - & - \\
\hline & Taiwan-yamacha & 2 & - & - \\
\hline & Shan & 1 & - & - \\
\hline & Abo & 1 & - & - \\
\hline & Ay & 1 & 1 & - \\
\hline \multirow[t]{6}{*}{ var. sinensis } & Japanese cultivars & 18 & 27 & 6 \\
\hline & $\mathrm{Cd}$ & 13 & 32 & 4 \\
\hline & $\mathrm{Cn}$ & 6 & 12 & 1 \\
\hline & $\mathrm{Cm}$ & 1 & 2 & 1 \\
\hline & $\mathrm{Ck}$ & 1 & 3 & - \\
\hline & $\mathrm{Cp}$ & - & 1 & - \\
\hline var. assamica & & 81 & 2 & 0 \\
\hline var. sinensis & & 39 & 77 & 12 \\
\hline Total & & 120 & 79 & 12 \\
\hline
\end{tabular}


Table 3. Characteristics of Japanese cultivars compared with other types of var. sinensis

\begin{tabular}{lcccc}
\hline \hline Variety & Type & No. of cultivars or lines & Parameter a & $\mathrm{x}_{\mathrm{o}}^{\text {a) }}$ \\
\hline var. sinensis & Others & 449 & $0.310^{*}$ & $156.3 \pm 5.2^{\mathrm{b})}$ \\
var. sinensis & Japanese cultivar & 163 & $0.348^{*}$ & $156.7 \pm 7.5$ \\
\hline
\end{tabular}

a): Effective accumulated temperature $(\mathrm{x}$ at $\mathrm{y}=0)$.

b): Standard deviation.

*indicates significant difference at $\mathrm{P}<0.01$ (Tukey multiple range test).

Table 4. Extremely late cultivars/lines

\begin{tabular}{lcc}
\hline \hline Variety & Type & No. \\
\hline var. assamica & Taiwan-yamacha & 44 \\
& Shan & 7 \\
& Ak & 3 \\
& Ai & 2 \\
BUM & 2 \\
var. sinensis & Abo & 1 \\
Total & F & 1 \\
& Japanese cultivars & 1 \\
& & 7 \\
\hline
\end{tabular}

exhibit more rapid growth for leaf opening than the other types, with a significant difference at the 0.01 level (Tukey multiple range test), suggesting that this study coincided with the direction of tea breeding in Japan. Moreover, the standard error for $\mathrm{x}_{0}$ was larger in the Japanese cultivars, indicating that Japanese cultivars include a wide range of early flushing lines to supply a wide range of harvesting periods. In this regard, more could be learned from the diversity of early flushing, as shown in Table 4. Sixty eight extremely late flushing lines were obtained from the 1,300 lines tested. These selected lines showed the same as or later flushing times than the famous Japanese late cultivar 'Yamatomidori'. Among the extremely late lines, Taiwan-yamacha accounted for the majority (44 lines) of the lines selected. Taiwanyamacha is grown predominantly in the highlands of Taiwan for the production of pan-fired semi-fermented (Oolong and Pouchong) tea. Wachira ${ }^{20}$ pointed out the uniqueness of Taiwan-yamacha based on cluster analysis. The introduction of extremely late lines like Taiwanyamacha has certainly contributed to spreading the range of flushing and harvesting, leading to the rational management of tea fields and factories.

The use of model parameters with effective accumulated temperature in tea breeding is a suitable method for selecting lines that are both early flushing and rapidly growing, because it is based on a single genetic character, sensitivity to temperature. The effectiveness of this method, however, has yet to be reconfirmed by the analy- sis of the performance among selected lines. Future studies with the developed model will confirm this effectiveness.

\section{References}

1. Amma, S. (1986) Identification of tea clones (Camellia sinensis (L.) O. Kuntze) by pubescence on the under surface of young leaves. In Development of new technology for identification and classification of tree crops and ornamentals, eds. Kitaura, K. \& Kozai, I., Fruit Tree Res. Stn, MAFF, Japan, 19-24.

2. Banerjee, B. (1988) Cup that cheers. Nature, 332, 580.

3. Banerjee, B. (1992) Botanical classification of tea. In Tea, eds. Wilson, K. C. \& Clifford, N. M., Chapman and Hall, London, UK. 25-51.

4. Burgess, P. J. \& Carr, M. K. V. (1997) Responses of young tea (Camellia sinensis) clones to drought and temperature. 3. Shoot extension and development. Expl. Agric., 33, 367-383.

5. Carr, M. K. V. \& Stephens, W. (1992) Climate, weather and the yield of tea. In Tea, eds. Wilson, K. C. \& Clifford, N. M., Chapman and Hall, London, UK. 87-135.

6. Kayumi, S., Toyao, T. \& Kuroki, S. (1978) Return period of the late frost damage influenced by earliness of bud opening of tea clones. Tea Res. J., 47, 11-16 [In Japanese with English summary].

7. Magoma, G. et al. (2000) The use of catechins as biochemical markers in diversity studies of tea (Camellia sinensis). Genet. Resour. Crop Evol., 47, 107-114.

8. Nakayama, A. \& Harada, S. (1962) Studies on the effect of temperature upon the growth of tea plant (Part 4). The effect of temperature upon the growth of young tea plant in summer. Bull. Tea Res. Stn., 1, 28-40 [In Japanese with English summary].

9. Nakayama, A., Kano, T. \& Sanai, H. (1966) Studies on the effect of temperature upon the growth of tea plant (Part 5). The effect of low temperature at night upon the growth of young tea plant. Tea Res. J., 25, 1-9 [In Japanese with English summary].

10. Owuor, P. O. et al. (1987) Differentiation of clonal teas by Terpene Index. J. Sci. Food Agric., 40, 341-345.

11. Sealy, J. R. (1958) A revision of genus Camellia. R. Hort. Soc., London, UK, 33-35.

12. Sekiya, N., Tanaka, K. \& Yamashita, M. (1979) Effects of air temperature on the shoot growth of tea plants. Tea Res. J., 49, 11-18 [In Japanese with English summary]. 
13. Smith, R. I., Harvey, F. J. \& Cannel, M. G. R. (1993) Clonal responses of tea shoot extension to temperature in Malawi. Expl. Agric., 26, 47-60.

14. Squire, G. R., Obaga, S. M. O. \& Othieno, C. O. (1993) Altitude, temperature and shoot production of tea in the Kenyan highlands. Expl. Agric., 29, 107-120.

15. Takahashi, T. et al. (1961) Studies on the frost damage of the tea garden at the frosty night and the emergent (physical) or cultural method to prevent the frost damage. Bull. Tea Div., Tokai-Kinki Agric. Exp. Stn. 8, 30-162 [In Japanese with English summary].

16. Takeda, Y. \& Toyao, T. (1982) Identification and classification of the green tea varieties by the morphological characters of flower organs. Tea. Res. J., 52, 1-6.

17. Tanton, T. W. (1982) Environmental factors affecting the yield of tea (Camellia sinensis). I. Effects of air temperature. Expl. Agric., 18, 47-52.

18. Tanton, T. W. (1982) Environmental factors affecting the yield of tea (Camellia sinensis). II. Effects of soil temperature, day length, and dry air. Expl. Agric., 18, 53-63.

19. Toyao, T. \& Takeda, Y. (1999) Studies on geographical diversity of floral morphology of tea plant (Camellia sinensis (L.) O. Kuntze) using the method of numerical taxonomy. Tea Res. J., 87, 39-57 [In Japanese with English summary].

20. Wachira, F., Tanaka, J. \& Takeda, Y. (2001) Genetic variation and differentiation in tea (Camellia sinensis) germplasm revealed by RAPD and AFLP variation. J. Hort. Sci. Biotech., 76 (5), 557-563.

21. Wickremaratne, M. R. (1981) Variation in some leaf characteristics in tea (Camellia sinensis L.) and their use in the identification of clones. Tea Q., 55, 183-189.

22. Yanase, Y. (1972) Growth of new tea shoot and its relation with temperature. Jpn. J. Crop Sci., 41 (Suppl. 2), 99-100 [In Japanese]. 